\title{
Isolation and characterization of Ehrlichia chaffeensis RNA polymerase and its use in evaluating p28 outer membrane protein gene promoters
}

\author{
Bonto Faburay, Huitao Liu, Lalitha Peddireddi and Roman R Ganta*
}

\begin{abstract}
Background: Ehrlichia chaffeensis is a tick-transmitted rickettsial pathogen responsible for an important emerging disease, human monocytic ehrlichiosis. To date how E. chaffeensis and many related tick-borne rickettsial pathogens adapt and persist in vertebrate and tick hosts remain largely unknown. In recent studies, we demonstrated significant host-specific differences in protein expression in E. chaffeensis originating from its tick and vertebrate host cells. The adaptive response of the pathogen to different host environments entails switch of gene expression regulated at the level of transcription, possibly by altering RNA polymerase activity.

Results: In an effort to understand the molecular basis of pathogen gene expression differences, we isolated native E. chaffeensis RNA polymerase using a heparin-agarose purification method and developed an in vitro transcription system to map promoter regions of two differentially expressed genes of the p28 outer membrane protein locus, p28-Omp14 and p28-Omp19. We also prepared a recombinant protein of E. chaffeensis $\sigma 70$ homologue and used it for in vitro promoter analysis studies. The possible role of one or more proteins presents in E. chaffeensis lysates in binding to the promoter segments and on the modulation of in vitro transcription was also assessed.

Conclusions: Our experiments demonstrated that both the native and recombinant proteins are functional and have similar enzyme properties in driving the transcription from E. chaffeensis promoters. This is the first report of the functional characterization of $E$. chaffeensis RNA polymerase and in vitro mapping of the pathogen promoters using the enzyme. This study marks the beginning to broadly characterize the mechanisms controlling the transcription by Anaplasmataceae pathogens.
\end{abstract}

\section{Background}

Ehrlichia chaffeensis is an obligate intracellular rickettsial pathogen and the causative agent of an important emerging zoonotic disease, human monocytic ehrlichiosis [1-4]. This Amblyomma americanum tick-transmitted pathogen causes infections in susceptible hosts (humans), host reservoirs (white-tailed deer), and less well described hosts such as the dog, goat and coyote [5-10]. E. chaffeensis has an unusual developmental cycle that requires growth and replication within

\footnotetext{
* Correspondence: rganta@vet.k-state.edu

Department of Diagnostic Medicine/Pathobiology, College of Veterinary Medicine, Kansas State University, Manhattan, KS 66506, USA
}

eukaryotic cells of vertebrate and tick hosts [11]. During its developmental cycle, there is conversion between two distinct morphological forms, the elementary bodies (EBs) and reticulate bodies (RBs) [12,13]. The EBs are the infectious form and upon entry into a host cell, they differentiate into metabolically active reticulate bodies (RBs), which are larger compared to EBs and divide by binary fission [12-14]. The reticulate bodies are also non-infectious forms [14]. Later in the developmental cycle, RBs convert back to EBs, which are released from infected cells $[12,14]$. The transformation of RBs to EBs by $E$. chaffeensis is observed in both vertebrate and tick hosts [15].
() Biomed Central

C 2011 Faburay et al; licensee BioMed Central Ltd. This is an Open Access article distributed under the terms of the Creative Commons Attribution License (http://creativecommons.org/licenses/by/2.0), which permits unrestricted use, distribution, and reproduction in any medium, provided the original work is properly cited. 
The mechanism by which the pathogen survives in dual hosts by adapting to changes in different host environments is unclear. Recent studies described the differential gene and protein expression profiles of the pathogen originating from tick and mammalian cell environments [15-18]. Moreover, E. chaffeensis organisms recovered from infected tick cells produce longerlasting infections in mice compared to the infection with organisms harvested from mammalian macrophages [19]. Differentially expressed proteins of E. chaffeensis included the predominant expression from outer membrane protein genes $p 28$-Omp19 and p28-Omp14 in mammalian and tick cell environments, respectively [15-19]. The adaptive response to different host environments requires altering the gene expression, often regulated at the transcriptional level by altering RNA polymerase (RNAP) activity [20]. A typical bacterial RNAP consists of five polypeptide chains; two $\alpha$ subunits, one each of $\beta$ and $\beta$ ' subunits, and a $\sigma$ subunit. The enzyme can take two forms, a holoenzyme containing all four different subunits or core polymerase that lacks a $\sigma$ subunit [21]. The capacity to synthesize RNA resides in the core polymerase and the role of a $\sigma$ subunit is to direct initiation of transcription from specific promoters [22,23]. The genome of E. chaffeensis includes two sigma factor genes; the homologs of the major bacterial sigma factor, $\sigma^{70}$, and an alternative sigma factor, $\sigma^{32}$ [24]. The current lack of established methods to stably transform, transfect, conjugate, or electroporate $E$. chaffeensis remain a major limiting factor to study mechanisms of gene expression by traditional methods. Mapping the functions of E. chaffeensis genes in vivo cannot be performed because genetic manipulation systems are yet to be established. To overcome this limitation, in a recent study we reported the utility of Escherichia coli RNAP as a surrogate enzyme to characterize E. chaffeensis gene promoters [25]. Although the E. coli RNAP proved valuable for mapping E. chaffeensis gene promoters, the extrapolation of the data requires further validation using the E. chaffeensis RNAP.

In this study, we developed a functional in vitro transcription system by utilizing G-less transcription templates [26] to drive transcription from two E. chaffeensis promoters. We described the partial purification and characterization of E. chaffeensis RNAP and its use in characterizing the transcriptional profiles of two p28Omp gene ( $p 28-O m p)$ promoters. In this study, we also described the recombinantly expressed $E$. chaffeensis sigma factor, $\sigma^{70}$, and its use in promoter analysis studies after its reconstitution with $E$. coli core enzyme. Modulatory effect of $E$. chaffeensis protein lysates on in vitro transcription is also described in this study to serve as the first step towards determining the regulatory mechanisms underlying gene expression in this pathogen.

\section{Results}

Isolation of $E$. chaffeensis RNA polymerase (E. chaffeensis RNAP)

E. chaffeensis DNA-dependent RNA polymerase (E. chaffeensis RNAP) was partially purified from the organisms grown in macrophage cultures by adapting heparin-agarose column purification method described earlier for other bacterial systems [27]. To determine the purity and polypeptide composition of the E. chaffeensis RNAP, several eluted fractions were electrophoresed on a polyacrylamide gel that was stained using silver nitrate (Figure 1A). The gel pattern revealed that the E. chaffeensis RNAP had a subunit structure similar to $E$. coli RNAP (that is also typical of other eubacteria) with five major subunits $\left(\alpha_{2}, \beta, \beta, \sigma\right)$. Western blot analysis confirmed the presence of E. chaffeensis $\sigma^{70}$ polypeptide when assessed using a heterologous E. coli anti$\sigma^{70}$ monoclonal antibody, 2G10 (Figure 1B). Amino acid alignment of the sequence of $E$. chaffeensis $\sigma^{70}$ polypeptide with $E$. coli $\sigma^{70}$ polypeptide revealed significant homology which also spanned to the putative binding site sequence of $2 \mathrm{G} 10$ antibody to $E$. coli $\sigma^{70}$ polypeptide [28,29] (Figure 2). The homology between amino acid residues of $\sigma^{70}$ polypeptides recognised by $2 \mathrm{G} 10$ antibody [28] is considerably higher between E. chaffeensis and E. coli than between E. chaffeensis and Chlamydia trachomatis. Protein BLAST search (at National Center for Biotechnology Information Bethesda, MD, USA) of the putative amino acid binding site sequence of 2G10 in E. coli $[28,29]$ against E. chaffeensis (Arkansas isolate) genome identified only one significant match (E-value of $1 \mathrm{e}^{-11}$ and having $69 \%$ identity) with $E$. chaffeensis RNAP $\sigma^{70}$ polypeptide, RpoD.

In support of testing the functionality of $p 28-O m p 14$ and $p 28-0 m p 19$ gene promoters, we constructed in vitro transcription templates, pRG147 and pRG198, by cloning the promoter regions of the genes into the pMT504 plasmid (Figure 3). The plasmid pMT504 is a G-less cassette containing two transcription templates cloned in opposite directions to aid in driving transcription from promoters introduced upstream of the G-less cassette sequences [26]. (The promoter segments were amplified from E. chaffeensis genomic DNA using the primers listed in Table 1.) The functionality of the promoters of $p 28-O m p 14$ and $p 28-O m p 19$ in correct orientation, in plasmids pRG147 and pRG198, was initially confirmed using $E$. coli holoenzyme containing its $\sigma^{70}$ polypeptide (Figure 4). Subsequently, transcriptional activity of the heparin-agarose purified RNAP fractions was evaluated. E. chaffeensis RNAP activity was detected in purified pooled fractions (data shown for pRG198 in 


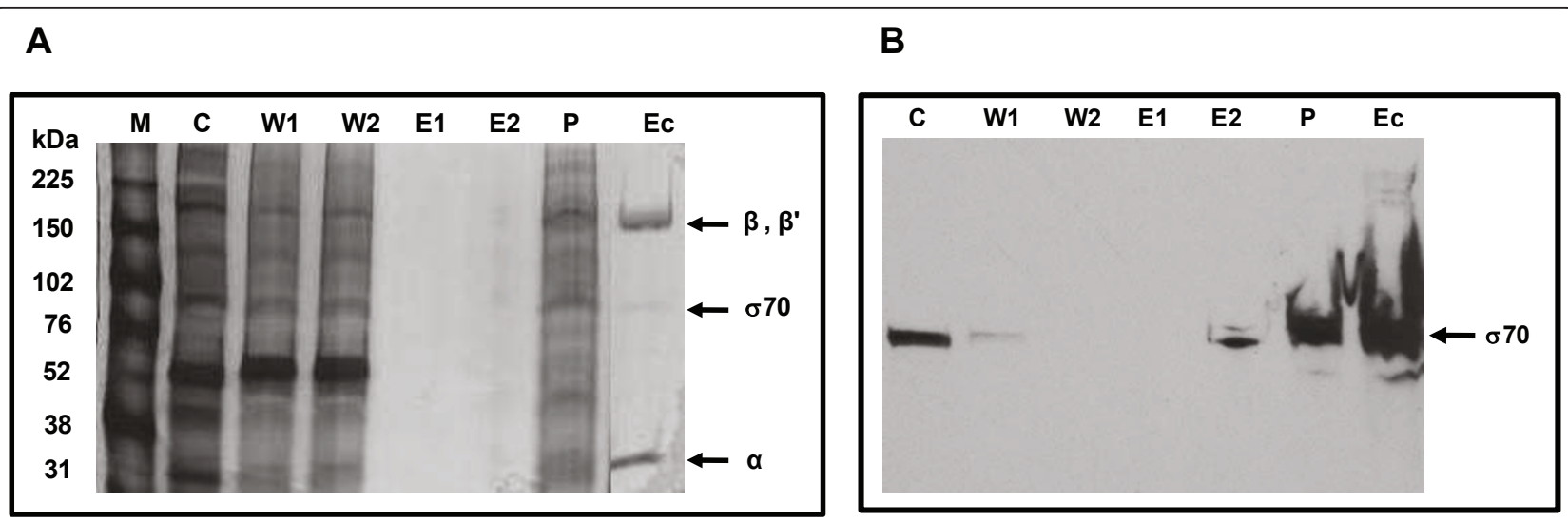

Figure 1 E. chaffeensis RNA polymerase purification by employing heparin agarose column purification method. A) Silver-stained SDSPAGE gel profile of heparin agarose purified fractions of $E$. chaffeensis RNA polymerase. $M$, protein standards $(\mathrm{kDa}) ; \mathrm{C}, E$. chaffeensis crude lysate; W1, first wash fraction from the column; W2, second column wash; E1, first elution fraction; E2, second elution fraction; P, pooled dialyzed fractions of eluted fractions 3 to 6; Ec, E. coli holoenzyme from Epicenter ${ }^{\circledR}$ B) Western blot analysis of the proteins resolved in panel A with $E$. coli anti-sigma70 monoclonal antibody, 2 G10.

Figure 4). The purified enzyme is completely inhibited in the presence of anti- $\sigma^{70}$ monoclonal antibody, 2G10, or in the presence of rifampicin (Figure 4). Further characterization using varying salt concentrations showed that the enzyme was active in presence of potassium acetate up to $200 \mathrm{mM}$ concentration and was inhibited at $400 \mathrm{mM}$ (Figure 5A), and the optimum concentration for activity of the enzyme for sodium chloride was observed at $80 \mathrm{mM}$ (Figure 5B).

\section{In vitro transcription by recombinant $E$. chaffeensis- $\sigma^{70}$}

We reconstituted E. coli RNAP core enzyme with recombinantly expressed $E$. chaffeensis $\sigma^{70}$ and the resulting holoenzyme effectively transcribed the promoters of $p 28-O m p 14$ and $p 29-O m p 19$ (data presented for p28-Omp 19 promoter in Figure 6), but the core enzyme alone or recombinant $E$. chaffeensis $\sigma^{70}$ alone did not drive the transcription. Saturation of the purified enzyme with recombinant $\sigma^{70}$ also resulted in enhanced transcriptional signals (Figure 6). General transcriptional profile of both the reconstituted enzymes in the presence of varying potassium acetate concentrations were similar (Figure 7), although a relatively stronger transcriptional signal at $400 \mathrm{mM}$ salt concentration was detected for $E$. coli core enzyme saturated with $E$. chaffeensis recombinant $\sigma^{70}$ subunit (Figure 7).

\section{Modulation of $E$. chaffeensis RNAP activity by whole-cell protein}

We evaluated the effect of $E$. chaffeensis whole-cell protein lysate, prepared from the bacteria grown in macrophage cell line, on transcription of $p 28$-Omp14 and $p 28$ Omp19 constructs using the native purified enzyme. The resulting transcripts were analyzed by two independent methods; densitometry of radiolabeled transcripts and the Taq-Man probe-based, real-time RTPCR. These analyses showed enhanced transcriptional activity in the presence of $4 \mu \mathrm{g}$ of $E$. chaffeensis wholecell lysate. Densitometric analysis revealed a 1.8-fold increase in transcriptional signal for the $p 28$-Omp 14 promoter construct and a 2.1-fold increase for $p 28$ Omp19 construct (Table 2). Addition of the same amount of protein yielded a similar fold increases when transcription was assessed with $E$. coli core enzyme saturated with $E$. chaffeensis recombinant $\sigma^{70}$. No transcription occurred with the addition of whole-cell lysate alone in the absence of an enzyme, a potential source of E. chaffeensis RNAP. Similarly, the addition of boiled lysate did not cause any change in transcriptional signals. Quantitation by real-time RT-PCR for the calculation of fold increase in transcription in the presence of E. chaffeensis whole-cell protein lysate was carried out as described previously [30,31]. Transcription of $p 28$ Omp19 construct with purified E. chaffeensis RNAP, as quantified by real-time RT-PCR, showed a 2.24 fold enhancement in the presence of $4 \mu \mathrm{g}$ of the protein lysate, whereas transcription of $p 28$-Omp 14 promoter construct resulted in a 1.81 fold-enhancement (Table 2), indicating a higher degree of agreement between the data generated by densitometric and real-time RT-PCR methods of quantitation (Table 2).

EMSA analysis of upstream sequences of p28-Omp14 and p28-Omp19 promoters

Electrophoretic mobility shift assay (EMSA) experiments utilizing the complete promoter regions of the $p 28$ Omp14 and p28-Omp19 of E. chaffeensis showed promoter-specific binding of tick cell- or macrophage- 


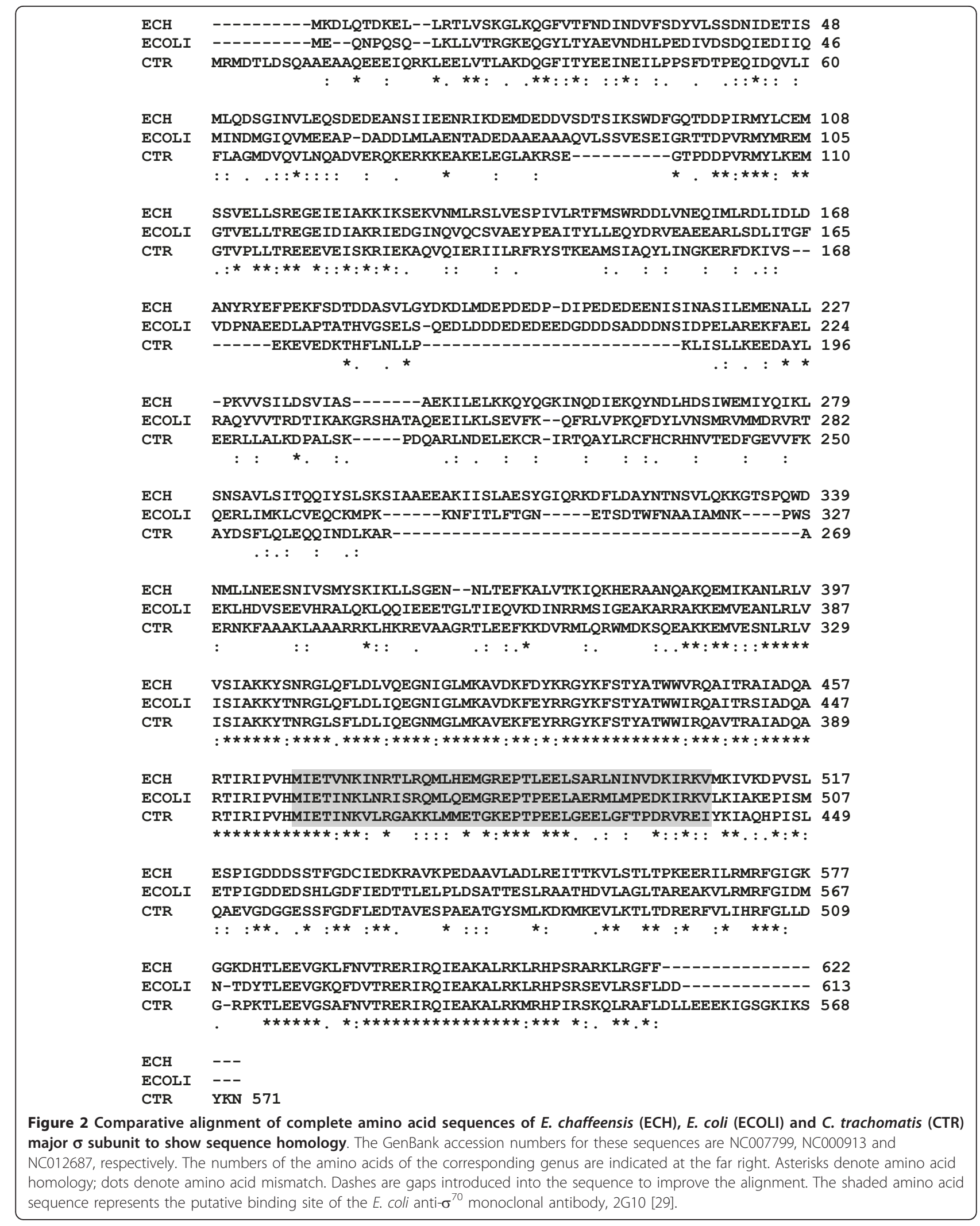




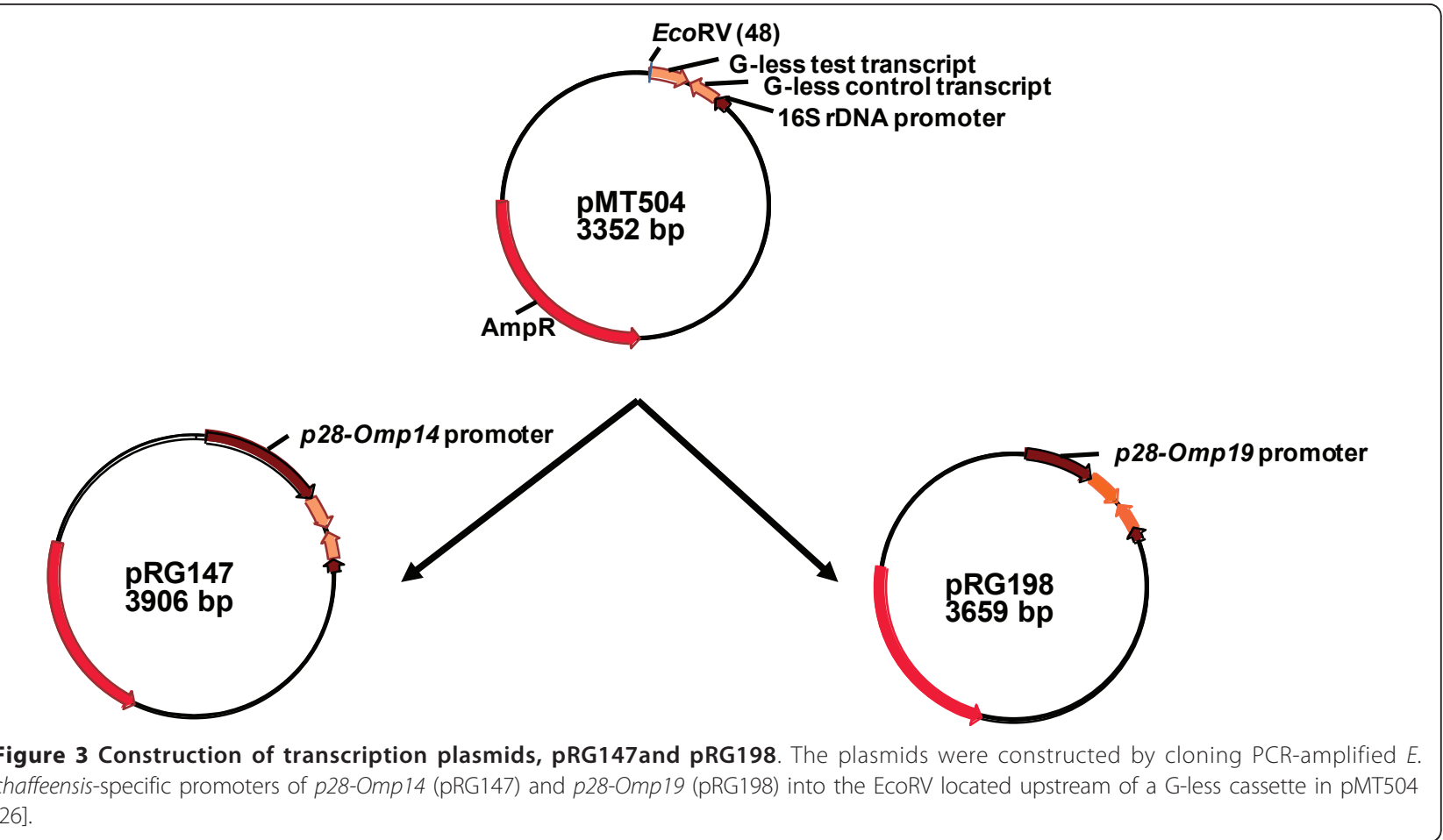

derived E. chaffeensis proteins (not shown). Addition of 50 ng of specific competitor DNAs consisting of unlabeled full length promoter DNA of $p 28-O m p 14$ or $p 28$ Omp19 abolished the shift of DNA-protein complex migration for both promoter regions. To further assess the interactions of Ehrlichia proteins with putative upstream sequences, five biotin-labelled short upstream DNA segments of $p 28-O m p 14$ (probes P1 to P5) (Figure 8A) and two DNA segments of p28-Omp19 (P6 and P7) (Figure $8 \mathrm{~B}$ ) promoters were prepared and used in the EMSA experiments. The promoter sequences of genes 14 and 19 included direct repeats and palindromic sequences [25]. The probes included one or more of the sequences. Three of the five probes for the $p 28-O m p 14$ promoter region exhibited significant shift in mobility in the presence of protein lysate from macrophage derived E. chaffeensis compared to the controls which contained probe alone with no lysate added or when non-specific protein was added to the probe fragments (Figure 9A). A shift in mobility was also noted in the interaction with one probe segment of the $p 28$-Omp19 promoter region when the protein lysate was added (Figure 9B). Addition of a 50-fold excess of unlabeled specific-competitors in the binding reactions significantly reduced the mobility shift of the probes. Densitometry analysis of the mobility shifted fragments differed for each probe compared to the non-shifted fragments. The P1 probe had $84 \%$ shift which reduced to $29 \%$ when competitor DNA was added; P2 and P3 probes had about 31\%, and
$27 \%$ shifts, respectively, and the shifts for these probes were completely abolished in the presence of specific competitors. The $p 28-O m p 19$ promoter region probe had about $23 \%$ shift which was reduced to $10 \%$ in the presence of specific competitor.

\section{Discussion}

A major impediment to the study of regulation of gene expression in the human monocytic ehrlichiosis pathogen, E. chaffeensis, is the absence of an experimental genetic manipulation system due to the inability to stably transform the organism. To partially overcome this constraint, we constructed plasmid transcription templates by transcriptional fusion of $p 28-O m p 14$ and $p 28$ Omp19 promoters to a G-less transcriptional template and isolated $E$. chaffeensis RNAP to create a system for transcriptional analysis in vitro, similar to studies reported for Chlamydia species [20,26,32-35]. We adapted the bacterial RNAP purification methods reported in the literature $[21,27,36,37]$ to recover functionally active $E$. chaffeensis RNAP. The procedure has been modified from a single-column purification method used for RNAP from E. coli, Bacillus subtilis, Chlamydia trachomatis, Rickettsia prowazekii and to recover the enzymes from several other bacterial organisms $[21,27,37]$. The purification steps involved the use of sodium deoxycholate, a bile salt often used in cell lysis but reportedly effective in the isolation of membrane proteins and in affinity chromatography by 
Table 1 Primer pairs and probes used in this study

\begin{tabular}{|c|c|c|c|}
\hline Primers/probes & Sequence & ${ }^{1}$ Orientation & Reference \\
\hline \multicolumn{4}{|c|}{ For cloning $p 28-O m p 14$ and $p 28-O m p 19$ promoters into pMT504 } \\
\hline RRG217 (p28-Omp14) & 5"-ttgctcaaccataaaataatggga & $\mathrm{F}$ & 25 \\
\hline RRG695 (p28-Omp14) & 5"-taaaaatttaagaataatgaaag & $\mathrm{R}$ & This study \\
\hline RRG185 (p28-Omp19)*\# & 5"-GACTCTAGActtttaattttattattgccacatg & $\mathrm{F}$ & 25 \\
\hline RRG696 (p28-Omp19) & 5"-aaataaattaacaatagtagaag & $\mathrm{R}$ & This study \\
\hline \multicolumn{4}{|c|}{ For cloning RpoD gene into $\mathrm{pET} 32$} \\
\hline RRG742* & 5"-GAGCCATGGcttaacaaattctatattttccctaactc & $\mathrm{F}$ & This study \\
\hline RRG743* & 5"-CGCTCGAGttaactattgatattacaatgacctagt & $\mathrm{R}$ & This study \\
\hline \multicolumn{4}{|c|}{ For TaqMan RT-PCR of test G-less transcripts } \\
\hline RRG766 & 5"-ccttcctccatctataccac & $\mathrm{F}$ & This study \\
\hline RRG767 & 5"-gagagtgaatgatgatagatttg & $\mathrm{R}$ & This study \\
\hline RRG765 (TaqMan Probe) & 5"-cattattcctcctatcttctcctcttctc & & This study \\
\hline \multicolumn{4}{|c|}{ For TaqMan RT-PCR of control G-less transcripts } \\
\hline RRG769 & 5"-tactcacccaatactcccta & $\mathrm{F}$ & This study \\
\hline RRG770 & 5"-gtggaatgagaaatgagtgt & $\mathrm{R}$ & This study \\
\hline RRG768 (TaqMan Probe) & 5"-cttatcctctcctcacctctccctc & & This study \\
\hline \multicolumn{4}{|l|}{ For sequencing pRG198 } \\
\hline $\mathrm{M} 13 \mathrm{~F}-40$ & 5"-gttttcccagtcacgac & & Commercial \\
\hline \multicolumn{4}{|c|}{ p28-Omp14 promoter EMSA probes } \\
\hline \multicolumn{4}{|l|}{ Full length probe } \\
\hline RRG $217^{* *}$ & & $\mathrm{~F}$ & \\
\hline RRG 218 & 5' gttaataaaccttttataaaag & $\mathrm{R}$ & 25 \\
\hline \multicolumn{4}{|l|}{ Probe $1(\mathrm{P} 1)$} \\
\hline$\overline{R R G 217^{* *}}$ & & $\mathrm{~F}$ & \\
\hline RRG623 & 5"-ggtttagccattttaaatgtg & $\mathrm{R}$ & This study \\
\hline \multicolumn{4}{|l|}{ Probe $2(\mathrm{P} 2)$} \\
\hline RRG267 & 5"-cagttaactttctgtaaacttc & $\mathrm{F}$ & 25 \\
\hline RRG623 & 5"-ggtttagccattttaaatgtg & $\mathrm{R}$ & This study \\
\hline \multicolumn{4}{|l|}{ Probe $3(\mathrm{P} 3)$} \\
\hline RRG269 & 5"-cgttttctgctttattagaatg & $\mathrm{F}$ & 25 \\
\hline RRG625 & 5"-gtacatgcattatgagcaaatc & $\mathrm{R}$ & This study \\
\hline \multicolumn{4}{|l|}{ Probe 4 (P4) } \\
\hline RRG270 & 5"-gttccgtatttattaatatatg & $\mathrm{F}$ & 25 \\
\hline RRG626 & 5"-ctatacttaactttactactta & $\mathrm{R}$ & This study \\
\hline \multicolumn{4}{|l|}{ Probe 5 (P5) } \\
\hline RRG272 & 5"-ggataagtactttagcaagtgg & $\mathrm{F}$ & 25 \\
\hline RRG627 & 5"-gtctagaatataaaatttctttc & $\mathrm{R}$ & This study \\
\hline \multicolumn{4}{|c|}{ p28-Omp19 promoter EMSA probes } \\
\hline \multicolumn{4}{|l|}{ Full length probe } \\
\hline RRG $185^{* *}$ & & $\mathrm{~F}$ & 25 \\
\hline RRG 445 & $5^{\prime}$ atataacctaatagtgacaaataaattaac & $\mathrm{R}$ & This study \\
\hline \multicolumn{4}{|l|}{ Probe 6 (P6) } \\
\hline RRG185** & & $\mathrm{F}$ & 25 \\
\hline RRG628 & 5"-gcacttataaactagtccc & $\mathrm{R}$ & This study \\
\hline \multicolumn{4}{|l|}{ Probe 7 (P7) } \\
\hline RRG276 & 5"-gtgctgttttctcacctttacac & $\mathrm{F}$ & 25 \\
\hline RRG629 & 5"-cttttgtaaggaaaatttaatata & $\mathrm{R}$ & This study \\
\hline
\end{tabular}

${ }^{1} \mathrm{~F}$, forward primer; $\mathrm{R}$, reverse primer

* Text in capital letters refers to sequences inserted for creating restriction enzyme sites

"Text in bold and italics letters refers to 7 nucleotides of coding sequence from the 3 " end of p28-Omp18 gene used in the primer

** Primer sequences were presented only once when a primer was described for the first time. 
preventing non-specific binding [36]. This property may be critical for the recovery of active enzyme, since previous studies in $R$. prowazekii, a closely related species, showed that up to $62 \%$ of total RNAP activity was associated with membrane proteins [27]. The heparin-agarose purification step is known to remove RNAP inhibitors and endogenous DNA [27]. The recovered E. chaffeensis enzyme showed transcriptional activity for both $p 28$-Omp14 and $p 28-O m p 19$ promoters and marked the first study describing RNAP activity of E. chaffeensis. SDS-PAGE profile suggested that the enzyme is partially pure and $E$. chaffeensis RNAP has a typical bacterial holoenzyme composition with five major subunits, $\alpha_{2}, \beta, \beta^{\prime}$, and $\sigma$.

The enhanced RNAP activity following addition of E. chaffeensis recombinant sigma 70 suggests that the preparation had less than stoichiometric amounts of the sigma factor, which is consistent with findings of the recovery of $E$. coli RNAP when employing similar procedures [22,27]. Previous studies suggest that RNAPs purified by heparin-agarose chromatography methods are only about $30 \%$ saturated with the major sigma factor, $\sigma^{70}[21]$ and do not co-purify with alternative sigma factors, such as a $\sigma^{32}$ homolog [20].

In this study, we presented evidence that the major E. chaffeensis sigma subunit, $\sigma^{70}$, was also recognized by a heterologous $E$. coli anti- $\sigma^{70}$ monoclonal antibody, 2G10. Functional studies with the 2 G10 suggest that this antibody can effectively inhibit in vitro transcriptional activity of E. coli [29] and C. trachomatis RNAP holoenzymes [28]. Similarly, this antibody inhibited the E. chaffeensis RNAP activity. These data are consistent with our bioinformatic analysis that the putative $2 \mathrm{G} 10$ antibody binding site sequences of $E$. coli and $E$. chaffeensis $\sigma^{70}$ subunits of RNAP share high degree of homology. Transcriptional inhibition of the enzyme by the anti- $\sigma^{70}$ monoclonal antibody and rifampin, a potent inhibitor of prokaryotic RNAP $[27,38]$, demonstrates that the in vitro transcriptional activity in our study was due to the isolated E. chaffeensis RNAP.

Transcriptional profiles depicting salt tolerance of purified enzymes have been described for prokaryotes, such as, C. trachomatis and E. coli [20,39]. In E. coli, transcription of a $\sigma^{70}$-regulated promoter decreases dramatically between $100 \mathrm{mM}$ and $150 \mathrm{mM}$ potassium acetate [39], whereas $\sigma^{66}$-dependent promoter activity of Chlamydia is completely inhibited at $400 \mathrm{mM}$ concentration [20]. The purified E. chaffeensis RNAP, reported in this study, also showed a similar range of salt tolerance as observed for other bacterial $\sigma^{70}$ dependent RNAPs. For example, the enzyme showed optimum transcriptional activity at $80 \mathrm{mM}$ sodium chloride, a slight difference from the optimal $50 \mathrm{mM}$ concentration reported for the $R$. prowazekii RNAP [27]. The minor differences in the salt tolerance properties may be unique to E. chaffeensis RNAP.

Previous studies suggest that RNAP fractions purified by heparin-agarose chromatography methods are typically about $30 \%$ saturated with the major sigma subunit [20]. Thus the presence of free core enzymes in the preparation allows reconstitution studies or saturation with recombinant sigma factors to enhance transcription in vitro. Thus we prepared a purified recombinant $E$. chaffeensis $\sigma^{70}$ subunit and used for assessing transcriptional activity by saturation of the native enzyme or by reconstitution with $E$. coli core enzyme. Saturation of the purified RNAP with the recombinant subunit resulted in enhanced transcriptional signals. Reconstitution of $E$. coli core enzyme with $E$. chaffeensis recombinant $\sigma^{70}$ subunit had similar salt sensitivities to that of purified $E$. chaffeensis RNAP before and after saturating with the recombinant subunit. These data are consistent with earlier reports indicating that purified C. psittacci $\sigma^{66}$ was effective in stimulating transcription by $C$. trachomatis and C. psittaci RNAP preparations [32] and highlights that $E$. coli core enzyme reconstituted with E. chaffeensis sigma factor offers an alternative approach to in vitro characterization of E. chaffeensis promoters as described for C. trachomatis [20,33]. Previously, we and others reported the use of $E$. coli system in characterizing the promoters of E. chaffeensis [25,40]. The current study offers an additional advantage over the $E$. coli system in that it uses E. chaffeensis RNAP or E. coli core enzyme with $E$. chaffeensis recombinant $\sigma^{70}$.

Regulation of gene transcription in prokaryotes involves a complex network and is controlled at the stage of RNA synthesis in which transcription factors (TFs) are key components $[41,42]$. TFs play an important role in regulating the transcription of specific genes by acting on the DNA regulatory sequences within the gene promoters $[41,42]$. When a transcription factor binds to a specific promoter, it can either activate or repress transcription $[35,43,44]$. To investigate the possible modulatory role of $E$. chaffeensis proteins on transcription of promoters of two differentially expressed genes, $p 28-O m p 14$ and $p 28-O m p 19$, we prepared $E$. chaffeensis whole-cell protein lysate from macrophagederived bacteria and evaluated its effect on transcription in vitro. Addition of the macrophage cell infectionderived E. chaffeensis protein extracts resulted in enhanced transcription suggesting that promoters of the p28-Omp14 and p28-Omp19 genes may be regulated in response to changing environments of the pathogen. Importantly, the enhanced in vitro transcription observed in this study in response to addition of protein extracts suggests that the lysates contain transcription regulators. Given the differential expression of $p 28$ Omp14 and p28-Omp19 genes [15] in vertebrate and 


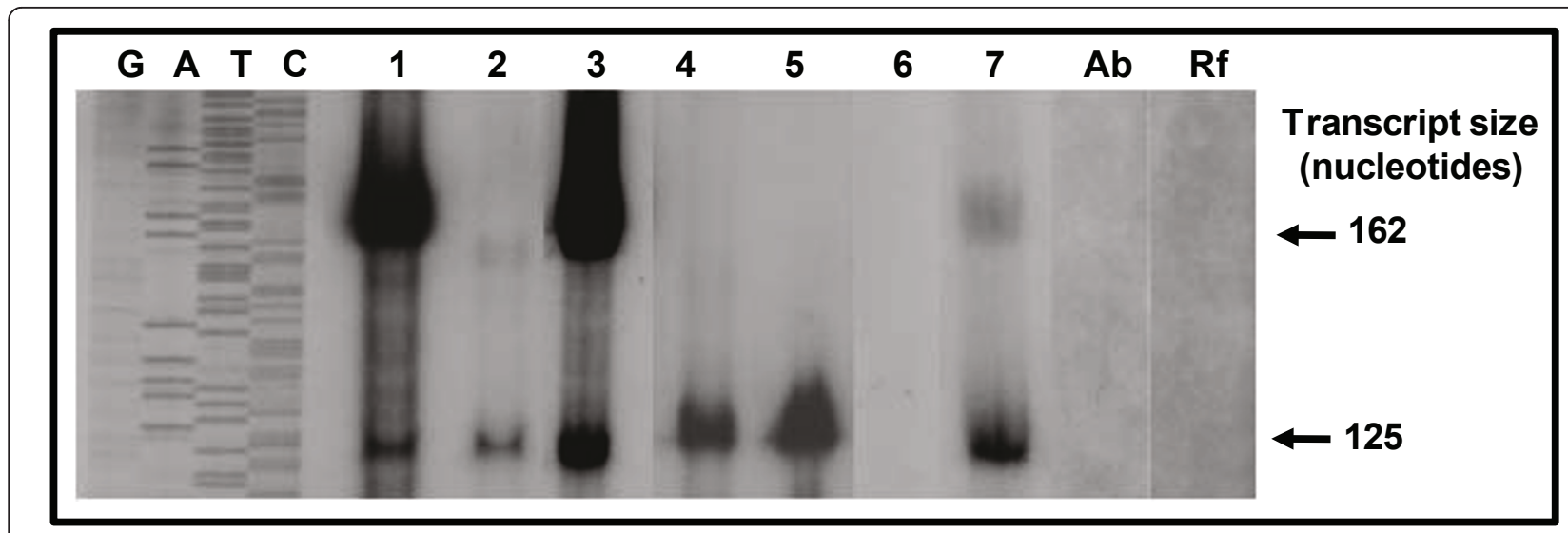

Figure 4 Transcriptional analysis of $E$. coli and E. chaffeensis RNAPs using p28-Omp 14 and 19 promoters. Transcription of pRG147 (lane 1), pRG147R (lane 2), pRG198 (lane 3), pRG198R (lane 4), pMT504 (lane 5) was assessed using E. coli holoenzyme or with E. coli core enzyme with pRG198 (lane 6). Transcription of pRG198 by HA-purified E. chaffeensis RNAP (lane 7); inhibition of transcription of E. chaffeensis RNAP by the addition of $4 \mu \mathrm{g}$ of $2 \mathrm{G} 10$ (Ab); inhibition of transcription of $E$. chaffeensis RNAP by addition of $25 \mu \mathrm{g} / \mathrm{ml}$ of rifampin (Rf). Inhibition assays were performed using pRG198. GATC, sequencing ladder generated using the plasmid pRG198 sequenced with primer M13F-40 to serve as the molecular weight markers.

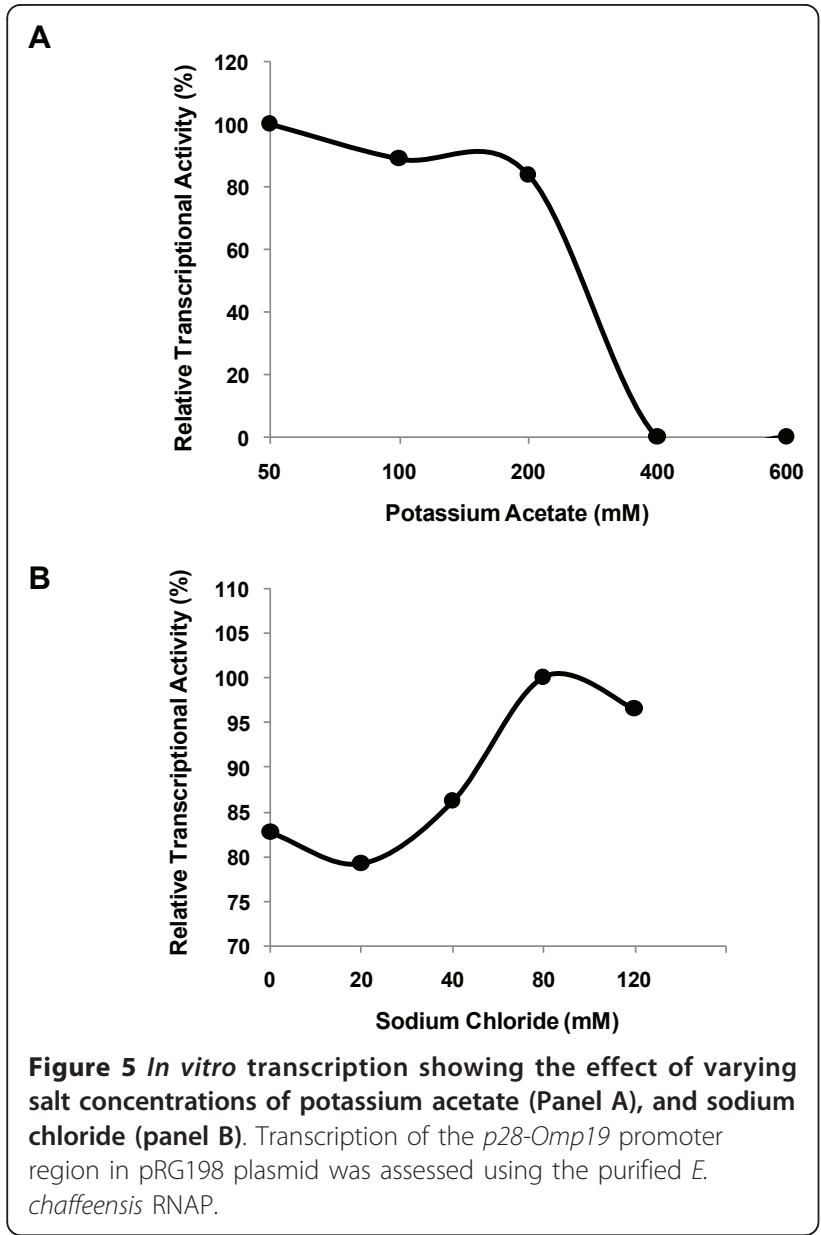

invertebrate hosts, the hypothesis that promoters of these genes may be under both positive and negative regulation in response to the changing host environments is also plausible. This hypothesis requires additional investigations, including the evaluation of the impact of tick cell environment. As an organism may express diverse array of transcription factors, it is highly likely that $E$. chaffeensis may regulate its gene expression via modulating the expression of transcription factors in support of maintaining its existence in dual hosts. Transcription regulation of a gene is a dynamic process and is responsive to environmental cues under which TFs

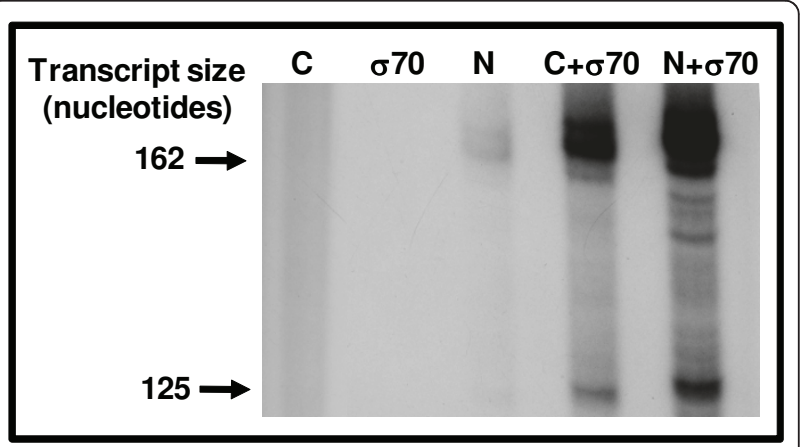

Figure 6 Transcriptional analysis of recombinant E. chaffeensis$\sigma^{70}$ using pRG198 transcriptional template. C, transcription products by $E$. coli core enzyme alone; $\sigma^{70}$, transcription products by the recombinant $E$. chaffeensis $\sigma^{70}$ protein; $N$, transcription products by purified $E$. chaffeensis RNAP; $C+\sigma^{70}$, transcription products by by $E$. coli core enzyme saturated with recombinant $E$. chaffeensis $\sigma^{70} ; N+\sigma^{70}$, transcription products by native purified enzyme saturated with recombinant $E$. chaffeensis- $\sigma^{70}$. 


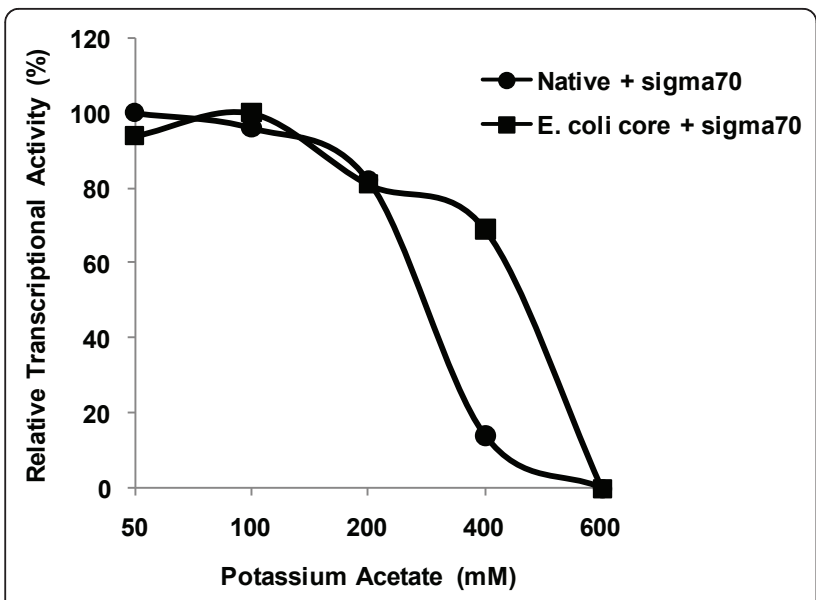

Figure 7 Transcription of pRG198 with varying potassium acetate concentrations showing transcription by $E$. chaffeensis RNAP saturated with the recombinant $\sigma^{70}$ and by $E$. coli core RNAP reconstituted with recombinant $\sigma^{70}$

trigger regulation $[39,45-47]$. This study shows the first evidence of stimulatory effect of $E$. chaffeensis whole-cell protein extract on the transcription of both $p 28-O m p 14$ and $p 28-O m p 19$ promoters in vitro. In our previous studies, we reported that the expression levels of the $p 28$ Omp14 and $p 28-O m p 19$ genes are different in macrophage and tick cell environments [16,19]. Although both the genes are transcriptionally active in macrophage host cell environment under in vitro and in vivo conditions, the expression levels for $p 28-O m p 19$ is higher for the bacteria in infected macrophages, whereas in tick cells $p 28-O m p 14$ is the predominantly expressed protein $[16,19]$. Consistent with those observations, the promoter constructs of both $p 28-O m p 14$ and $p 28-O m p 19$ genes remained active and enhanced when $E$. chaffeensis protein lysates prepared from macrophage culture derived organisms were added. Additional investigations are needed to further define the differences in the expression levels for the $p 28$-Omp14 and $p 28-O m p 19$ genes in macrophage and tick cell environments. A gene in a cell may be regulated by different TFs, and the contribution from different TFs may be variable under different environmental conditions [48]. Thus, more detailed investigations are needed to map quantitative differences in the transcription and to further assess the complex regulatory network of transcription in $E$. chaffeensis.

The current study provides the first evidence suggesting that E. chaffeensis whole-cell protein lysates contain regulatory proteins which modulate transcription of p28-Omp14 and p28-Omp19 promoters in vitro. In support of further testing the hypothesis that $E$. chaffeensis whole-cell protein lysates contain proteins that bind to putative regulatory DNA sequences of these promoters, EMSA experiments were performed. A shift in mobility of DNA fragments was observed for several partial or complete DNA segments of the promoter regions of both $p 28-O m p 14$ and $p 28-O m p 19$ genes. These data suggest that the promoter region contained regulatory DNA sequences that allowed binding of one or more $E$. chaffeensis proteins. The binding was specific as the addition of specific competitors considerably reduced the shift and the addition of a non-specific protein did not cause a shift. The binding of E. chaffeensis regulatory proteins to the DNA segments spanning putative DNA binding elements is consistent with previous studies on this organism [49] as well as in several other bacteria, including Anaplasma phagocytophilum [50-52], C. trachomatis $[34,35]$ and $B$. subtilis $[53,54]$ in which interaction of regulatory proteins with regulatory sequences have been demonstrated. The identity of DNA binding proteins and the location of protein binding sites remain to be determined.

\section{Conclusions}

In this study, we developed in vitro transcription assays using a G-less cassette and described methods to isolate native RNAP and the recombinant RNAP $\sigma 70$ subunit of $E$. chaffeensis. The value of using these tools in evaluating the promoters of two differentially expressed genes has been demonstrated. The application of these tools to the study of $E$. chaffeensis is new and important for furthering our understanding of the regulation of gene expression in this pathogen. Specifically, the tools will be valuable in studies to map specific interactions of $E$. chaffeensis proteins in driving differential gene

Table 2 Effect of macrophage-culture grown E. chaffeensis whole-cell lysate on the transcription of p28-Omp14 (pRG147) and p28-Omp19 (pRG198) promoter constructs quantitated by densitometry and real-time RT-PCR (fold change)

\begin{tabular}{|c|c|c|c|c|c|c|c|c|}
\hline \multirow[b]{2}{*}{ Template } & \multicolumn{4}{|c|}{ Densitometry } & \multicolumn{4}{|c|}{ Real-time RT-PCR } \\
\hline & $\begin{array}{l}\text { no lysate } \\
\text { (x } \pm \text { std) }\end{array}$ & $\begin{array}{l}\text { with lysate } \\
(x \pm \text { std) }\end{array}$ & fold increase & $p$-value* & $\begin{array}{l}\text { no lysate } \\
\text { (Ct } \pm \text { std) }\end{array}$ & $\begin{array}{l}\text { with lysate } \\
(C t \pm \text { std })\end{array}$ & fold increase & $p$-value* \\
\hline pRG147 & $83.3 \pm 1.8$ & $45.5 \pm 1.9$ & 1.8 & $<0.0001$ & $17.51 \pm 0.81$ & $16.64 \pm 0.23$ & 1.81 & 0.0174 \\
\hline pRG198 & $76.9 \pm 1.7$ & $35.7 \pm 1.6$ & 2.2 & $<0.0001$ & $17.48 \pm 0.08$ & $16.27 \pm 0.06$ & 2.24 & 0.0013 \\
\hline
\end{tabular}

\#volume of the unoccupied space available under the signal is quantitated

${ }^{*} p$-value of $\leq 0.05$ is significant 


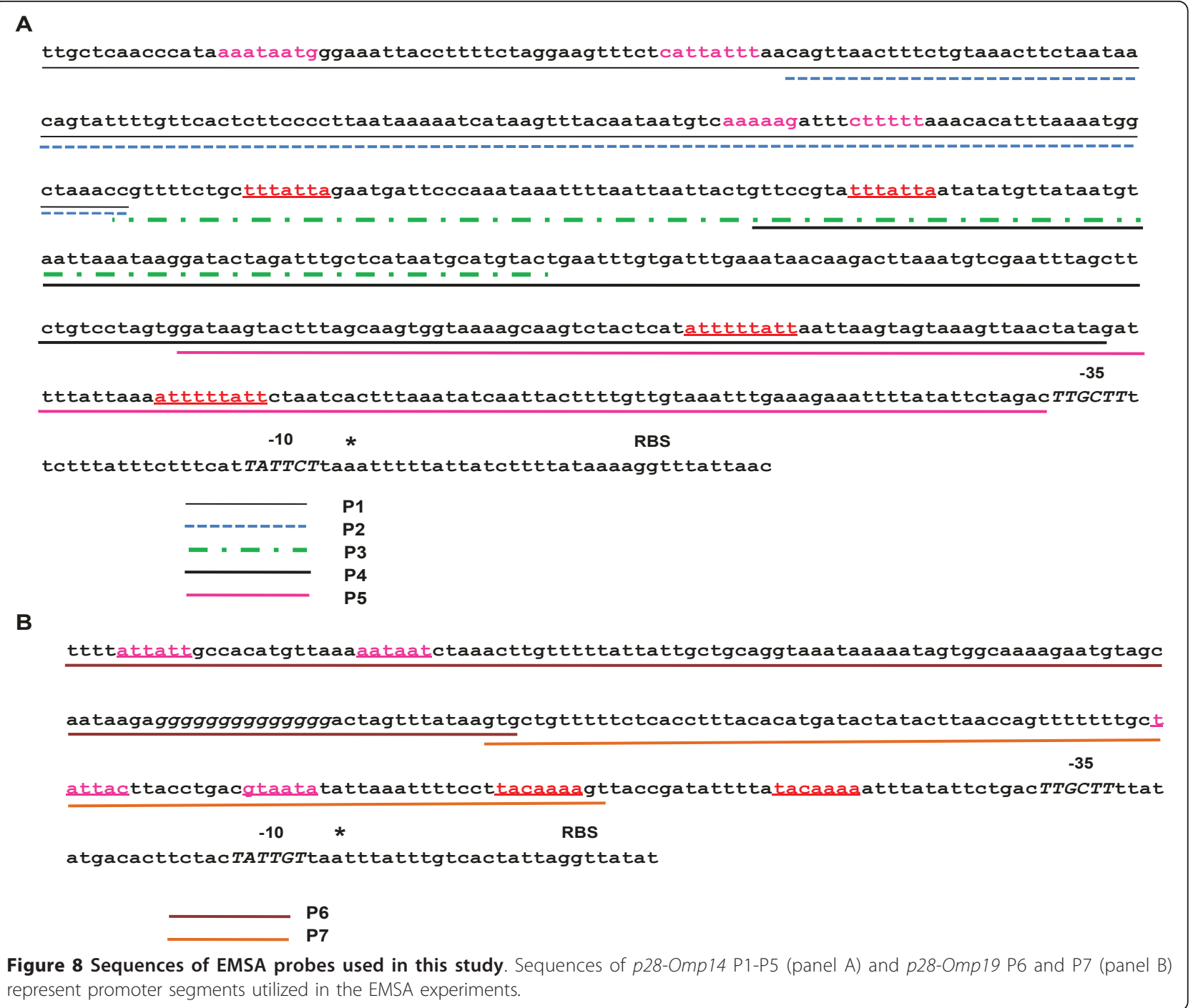

A

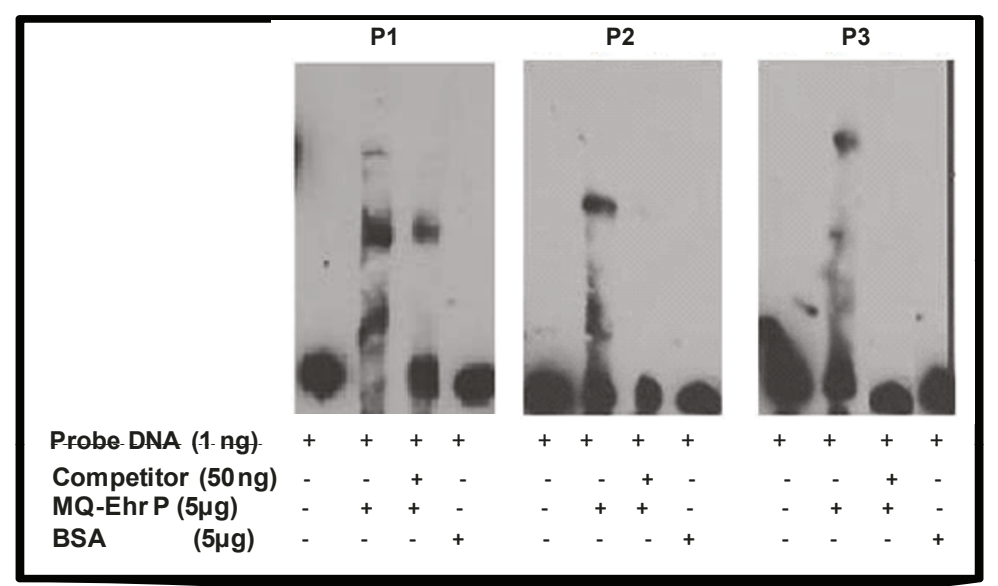

B

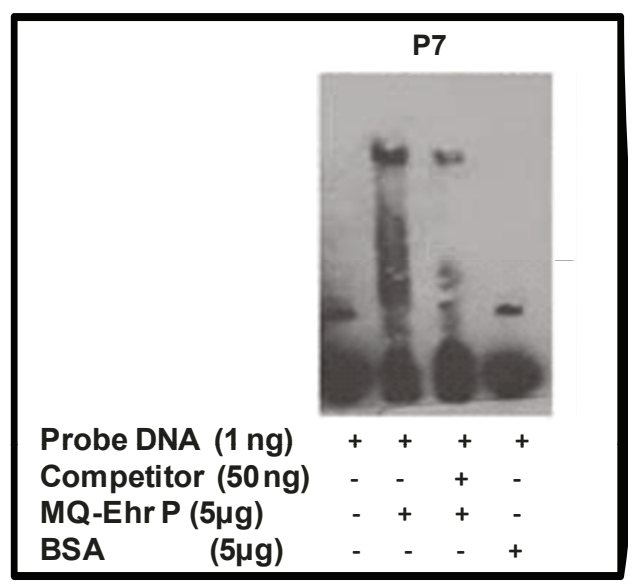

Figure 9 EMSA using short segments of three biotin-labeled probes of p28-Omp14 (panel A) and one p28-Omp19 (panel B) promoter segments. Addition of E. chaffeensis protein extracts (MQ-Ehr P) and unlabeled promoter DNA as a cold competitor (Competitor) or bovine serum albumin (BSA) as a non-specific protein control are indicated in captions at the bottom of the Figure for both the panels. 
expression influenced by vertebrate and tick host cell environments. This is the first report of in vitro transcription using native E. chaffeensis RNAP and E. coli RNAP core enzyme reconstituted with the recombinant E. chaffeensis $\sigma^{70}$ subunit. This study marks the beginning of a greater effort to broadly characterize the mechanisms that control the transcription in Anaplasmataceae pathogens in support of their growth in vertebrate and tick hosts.

\section{Methods}

\section{PCR conditions}

PCRs for amplification of E. chaffeensis p28-Omp14 and p28-Omp19 promoters were carried out in a $25 \mu \mathrm{l}$ reaction volume containing $0.2 \mu \mathrm{M}$ of each primer, $250 \mathrm{ng}$ of purified E. chaffeensis (Arkansas isolate) genomic DNA, $400 \mu \mathrm{M}$ of each of the four deoxyribonucleoside triphosphates, $1.5 \mathrm{mM} \mathrm{MgSO}_{4}$, $1 \mathrm{x}$ native HiFi PCR buffer $\left(60 \mathrm{mM}\right.$ Tris- $\left.\mathrm{SO}_{4}, 18 \mathrm{mM}\left(\mathrm{NH}_{4}\right)_{2} \mathrm{SO}_{4}\right), 2.5$ units $\mathrm{HiFi}$ polymerase. After the first denaturation step of DNA at $95^{\circ} \mathrm{C}$ for $2 \mathrm{~min}$, amplification was carried out for 45 cycles of denaturation at $95^{\circ} \mathrm{C}$ for $30 \mathrm{~s}$, annealing at $40^{\circ} \mathrm{C}$ for $30 \mathrm{~s}$ and extension at $72^{\circ} \mathrm{C}$ for $50 \mathrm{~s}$ and a final extension at $72^{\circ} \mathrm{C}$ for $2 \mathrm{~min}$.

\section{Construction of transcription plasmids}

The plasmid pMT504 is a G-less cassette plasmid containing two transcription templates cloned in opposite directions to aid in driving transcription from promoters introduced upstream of the G-less cassette sequences [26]. We constructed in vitro transcription templates, pRG147 and pRG198, by cloning the promoter regions of $p 28-O m p 14$ and $p 28-O m p 19$, respectively, into the pMT504 plasmid at EcoRV site (Figure 1). The promoter sequences selected for preparing these constructs included the sequences starting from the downstream first nucleotide of the termination codon of the upstream gene and up to the transcription start sites of the genes mapped in our previous study [25]. Plasmid pRG147 contained a 553 bp promoter region of $p 28$ Omp14 amplified from genomic DNA using primers RRG217 and RRG695 (Table 1). Similarly, plasmid pRG198 contained a 306 bp promoter region of $p 28$ Omp19 amplified by primers RRG185 and RRG696. All oligonucleotide primers used in this study were designed from the genome sequence data [24] and were synthesized at Integrated DNA Technologies, Inc. (Coralville, Iowa). Reverse primers for promoter segments included the transcription start sites of the respective promoters but excluding any guanosine residue downstream of the transcription initiation sites. This is to avoid transcription termination caused by incorporation methylated guanosine triphosphate present in the transcription reactions (outlined below under in vitro transcription).
The promoter inserts were also cloned in opposite orientation (pRG147R and pRG198R) to serve as negative controls to demonstrate promoter-specific in vitro transcription.

Transcription from pRG147, pRG198 or pMT504 plasmids results in a shorter 125-nucleotide transcripts encoded by a control transcription template positioned downstream of the Chlamydia trachomatis rRNA P1 promoter. The test transcription template contains a 153-nucleotide G-less cassette segments in the opposite direction to the control transcription template. This synthetic template results in the transcription of a 162 nucleotide transcript from the transcription start site for both the p28-Omp14 and 19 gene promoters. Supercoiled plasmids for use in the in vitro transcription assays were prepared using the QIAprep Spin Miniprep kit (Qiagen Inc., Valencia, CA) according to the manufacturer's instructions. The DNA sequences of the promoter templates were verified by restriction enzyme and sequencing analysis.

\section{In vitro transcription assays}

In vitro transcription reactions were performed in a 10 $\mu \mathrm{l}$ final reaction volume with the following components; $50 \mathrm{mM}$ Tris-acetate buffer $\mathrm{pH} 8.0$ containing $50 \mathrm{mM}$ potassium acetate, $8.1 \mathrm{mM}$ magnesium acetate, $27 \mathrm{mM}$ ammonium acetate, $80 \mathrm{mM} \mathrm{NaCl}, 2 \mathrm{mM}$ DTT, $400 \mu \mathrm{M}$ ATP, $400 \mu \mathrm{M}$ UTP, $2.1 \mu \mathrm{M}\left[\alpha-{ }^{32} \mathrm{P}\right]-\mathrm{CTP}\left(800 \mathrm{Ci} \mathrm{mmol}^{-}\right.$ ${ }^{1}$ for radioisotope detection method) or $400 \mu \mathrm{M} \mathrm{CTP}$ (for detection and quantification by real-time reverse transcription PCR), $100 \mu \mathrm{M}$ sodium salt of 3'-O-methylguanosine 5'-triphosphate, 18 units of RNasin, 5\% glycerol, $0.13 \mathrm{pmol}$ of supercoiled DNA template and $1 \mu \mathrm{l}$ (360 ng) of heparin-agarose purified E. chaffeensis RNAP or $0.5 \mu$ l of 1:10 dilution of $E$. coli core enzyme (Epicenter, Madison, WI) or $0.5 \mu \mathrm{l}$ of 1:10 dilution of $E$. coli $\sigma^{70}$-saturated holoenzyme (Epicenter, Madison, WI). For enzyme salt tolerance assays, potassium acetate and $\mathrm{NaCl}$ concentrations were varied over a range from 0 to $600 \mathrm{mM}$ and 0 to $120 \mathrm{mM}$, respectively. In transcription reactions using E. chaffeensis recombinant $\sigma^{70}$, RNAP holoenzyme was reconstituted by adding $360 \mathrm{ng}$ of recombinant protein to $0.5 \mu \mathrm{l}$ of $1: 10$ diluted $E$. coli core enzyme. Holoenzyme formation was allowed to occur by incubating the mixture on ice for $20 \mathrm{~min}$. To assess the modulatory effect on transcription, $4.0 \mu \mathrm{g}$ of $E$. chaffeensis protein lysate (preparation described below) was incubated for $20 \mathrm{~min}$ at room temperature with the transcription reaction mixture in the absence of an RNAP to allow binding of proteins to DNA elements of promoter segments. Next, $1 \mu \mathrm{l}$ of the purified E. chaffeensis RNAP was added to reaction mixture. In general, transcription reactions were incubated at $37^{\circ} \mathrm{C}$ for varying times of $7.5 \mathrm{~min}, 15 \mathrm{~min}$ or $30 \mathrm{~min}$ and the 
reactions were terminated by adding $7 \mu \mathrm{l}$ of stop solution (95\% formamide, $20 \mathrm{mM}$ EDTA, 0.05\% bromophenol blue and $0.05 \%$ xylene cyanol). Six microliters of the sample was electrophoresed on a $6 \%$ polyacrylamide sequencing gel containing $7 \mathrm{M}$ urea. The gels were dried and transcripts were visualized by exposing an $\mathrm{X}$ ray film to the gels. Autoradiographs were scanned on a HP SCANJET 5550 scanner (Hewlett-Packard ${ }^{\circledR}$ ).

\section{Isolation of $E$. chaffeensis RNAP}

The RNAP isolation method was a modified version from the heparin-agarose procedure described in $[21,27,55]$. E. chaffeensis Arkansas isolate was grown in confluent DH82 cells (malignant canine monocyte/ macrophage cells) in $300 \mathrm{~cm}^{2}$ culture flasks in 1 litre MEM tissue culture medium containing $7 \%$ fetal bovine serum (Gibco BRL ${ }^{\circledR}$ ) and $1.2 \mathrm{mM} \mathrm{L}$-glutamine [56]. DH82 cultures infected with $E$. chaffeensis having predominantly reticulate bodies (RB) were harvested $48 \mathrm{~h}$ post-infection by centrifugation at $1,000 \times \mathrm{g}$ for $10 \mathrm{~min}$ at $4^{\circ} \mathrm{C}$ in an Eppendorf 5810R centrifuge. (All centrifugation steps were performed using this centrifuge.) The purification steps were all performed at $4^{\circ} \mathrm{C}$. The pellet was resuspended in $25 \mathrm{ml}$ sucrose potassium glutamate (SPG) buffer (218 mM sucrose, $3.76 \mathrm{mM} \mathrm{KH}_{2} \mathrm{PO}_{4}, 7.1$ $\mathrm{mM} \mathrm{K} \mathrm{HPO}_{4}, 5 \mathrm{mM}$ potassium glutamate, $\mathrm{pH}$ 7.0) and host cells were lysed in a $40 \mathrm{ml}$ Wheaton homogenizer with pestle A. The lysate was centrifuged at $800 \times \mathrm{g}$ for $10 \mathrm{~min}$ in $50 \mathrm{ml}$ conical tubes to pellet host cell debris. Subsequent supernatant was centrifuged at $15,000 \times \mathrm{g}$ for $10 \mathrm{~min}$ to pellet the organisms. The RB pellet was resuspended in $2 \mathrm{ml}$ of freshly prepared lysis buffer [10 $\mathrm{mM}$ Tris- $\mathrm{HCl}$ ( $\mathrm{pH} 8.0$ ), $10 \mathrm{mM} \mathrm{MgCl}_{2}, 1 \mathrm{mM}$ EDTA, $0.3 \mathrm{mM}$ dithiothreitol (DTT), $7.5 \%$ glycerol (vol/vol), 50 $\mathrm{mM} \mathrm{NaCl}, 1 \mathrm{x}$ Amersham protease inhibitor mixture, and $150 \mu \mathrm{g}$ per $\mathrm{ml}$ of lysozyme]. Lysis was facilitated by three passages through 27.5 G needle. Sodium deoxycholate (at final concentration of $0.05 \%$ ) was added to the lysate and the suspension incubated for $30 \mathrm{~min}$ at $4^{\circ}$ C. The lysate was centrifuged at $10,000 \times \mathrm{g}$ for $10 \mathrm{~min}$ and the supernatant was collected and clarified by an additional centrifugation step for $5 \mathrm{~min}$.

The clarified supernatant was loaded onto pre-packed heparin-agarose column (type I-S, Sigma ${ }^{\circledR}$ ) previously equilibrated with buffer A [10 mM Tris $\mathrm{HCl}(\mathrm{pH}$ 8.0),10 $\mathrm{mM} \mathrm{MgCl}_{2}, 1 \mathrm{mM}$ EDTA, $0.3 \mathrm{mM}$ DTT, $7.5 \%$ glycerol and $50 \mathrm{mM} \mathrm{NaCl}$. The suspension was adsorbed for 60 min at $4^{\circ} \mathrm{C}$ and the column was washed by gravity with $20 \mathrm{ml}$ of buffer A for complete removal of unbound proteins. The bound proteins from the column were eluted by gravity with buffer A containing $0.6 \mathrm{M} \mathrm{NaCl}$ and $0.5 \mathrm{ml}$ fractions were collected. Based on previous analysis and calculation of the void volume of the column, fractions 3-6 were pooled and dialyzed overnight against storage buffer $[10 \mathrm{mM}$ Tris- $\mathrm{HCl}(\mathrm{pH} 8.0), 10$ $\mathrm{mM} \mathrm{MgCl} 2,0.1 \mathrm{mM}$ EDTA, $0.1 \mathrm{mM}$ DTT, $50 \%$ glycerol and $100 \mathrm{mM} \mathrm{NaCl}$ ] using Slide-A-Lyzer Gamma Irradiated Dialysis Cassette (Thermo Scientific, Illinois, USA). The fractions were stored at $-80^{\circ} \mathrm{C}$. RNAP activity of the dialyzed fraction was determined by in vitro transcription assay.

\section{Protein concentration}

Protein concentration of the HA purified RNAP fractions and E. chaffeensis whole-protein lysates were measured with the bicinchoninic acid protein assay reagent (Thermo Scientific, Illinois, USA) with bovine serum albumin as the protein standard.

\section{SDS-PAGE}

Proteins were analyzed by electrophoresis in 7.5\% sodium dodecyl sulphate-polyacrylamide gel (SDSPAGE), followed by silver staining according to the procedures provided by the manufacturer (G Biosciences, USA) or resolved proteins were transferred onto a nitrocellulose membrane, Hybond-ECL (Amersham Biosciences, Germany), for immunoblot analysis.

\section{Western blot (immunoblot) of RNAP extracts}

E. chaffeensis RNAP purified above was subjected to SDS-PAGE and the proteins were electroblotted for $2 \mathrm{~h}$ at $70 \mathrm{~V}$ to a sheet of nitrocellulose membrane. The membrane blot was blocked in a solution containing $10 \%$ nonfat dried milk (NFDM) freshly made in TTBS [0.1\% Tween-20 in $100 \mathrm{mM}$ Tris- $\mathrm{HCl}(\mathrm{pH} 7.5)$ and $0.9 \%$ $\mathrm{NaCl}]$ for $1 \mathrm{~h}$ at room temperature with gentle agitation. The blot was rinsed three times in TTBS and then was incubated for $1 \mathrm{~h}$ at room temperature or overnight at $4^{\circ} \mathrm{C}$ with anti-E. coli $\sigma^{70}$ antibody, 2G10 (Santa Cruz Biotechnology Inc., Santa Cruz, CA), diluted 1: 500 in $1 \%$ NFDM in TTBS solution. The blot was washed again three times with washing solution and then incubated for $1 \mathrm{~h}$ at room temperature with horseradish peroxidase-conjugated anti-mouse immunoglobulin G diluted 1:5000 in 1\% NFDM in TTBS solution. The blot was rinsed again three more times with TTBS to remove excess secondary antibody and detection was carried out using chemiluminescent detection reagents (Amersham ECL ${ }^{\mathrm{TM}}$, GE Healthcare).

\section{Properties of isolated E. chaffeensis RNAP}

Assays to determine the salt tolerance of the purified enzyme have been described above. Rifampin/rifampicin is a potent inhibitor of prokaryotic RNAPs, but not for eukaryotic RNAP [27]. As E. chaffeensis RNAP was recovered from organisms grown in eukaryotic cells (DH82), it may be potentially contaminated with eukaryotic RNAP. To confirm that the transcript formation is 
from E. chaffeensis RNAP but not from eukaryotic RNAP, in vitro transcription assays were performed in the presence of rifampin at a concentration of $25 \mu \mathrm{g} \mathrm{ml}$ 1 .

Functional studies with an E. coli RNAP monoclonal antibody (2G10) demonstrated that it can effectively bind to E. coli $\sigma^{70}$ and markedly inhibit in vitro transcriptional activity by RNAPs of E. coli [29] and C. trachomatis [28]. To further assess that in vitro transcriptional activity was due to E. chaffeensis purified RNAP but not from eukaryotic RNAP, we utilized the $E$. coli monoclonal antibody $2 \mathrm{G} 10$ in inhibition assays assuming that it blocks the E. chaffeensis RNAP similar to $C$. trachomatis RNAP. For this experiment, $4 \mu \mathrm{g}$ of 2 G10-antibody was added in transcription reactions and the production of transcripts were assessed by following the methods described above.

\section{Overexpression and purification of $E$. chaffeensis RpoD $\left(\sigma^{70}\right)$}

The entire RpoD ( $\sigma 70$ subunit gene) protein coding sequence, identified from the E. chaffeensis Arkansas isolate genome [24], was amplified by PCR and cloned into the pET32 plasmid (Novagen, Madison, WI) for producing recombinant protein. The PCR was performed using $p f u$ DNA polymerase (Promega, Madison, WI) and with the gene-specific PCR primers, RRG742 and RRG 743 (Table 1). To facilitate directional cloning, NcoI and XhoI restriction enzyme sites were engineered in the PCR product. The PCR product was subsequently cloned into pET32 plasmid at the above restriction sites after digesting both plasmid and inserts and ligating using T4 DNA ligase. Over expression of RpoD protein and its purification was carried out with methods similarly described elsewhere [20,57]. The concentration of the purified RpoD protein was approximately $180 \mathrm{ng} / \mu \mathrm{l}$, as determined by protein estimation method (described above).

\section{Quantification of transcription}

We carried out quantification of in vitro-generated RNA transcripts of $p 28-O m p 14$ and $p 28$-Omp19 promoters by densitometry and TaqMan probe-based real-time RTPCR. For densitometric analysis, we quantitated the signal intensity of radio actively labelled transcripts on Xray films using ImageQuant software 5.2 (Molecular Dynamics, Inc., Sunnyvale, CA). For real-time RT-PCR analysis, primers and TaqMan probes for the 162 and 125 nucleotide (nt) G-less cassettes were designed manually and optimized using Vector NTI Advance 11 software (Invitrogen, Carlsbad, CA). The primers and probes used for these assays were listed in Table 1. The TaqMan probe for the 162 nt cassette (RRG765) and the probe for the $125 \mathrm{nt}$ cassette (RRG768) have been labelled with reporter fluorescent dyes TET and ROX and quencher dyes Iowa Black FQ and Iowa Black RQ$\mathrm{Sp}$, respectively. Real-time RT-PCR was carried out using the SuperScript ${ }^{\mathrm{TM}}$ III One-Step RT-PCR reagents (Invitrogen, Carlsbad, CA). Each RT-PCR reaction contained the following: $1 \mathrm{x}$ reaction mix (containing 200 $\mu \mathrm{M}$ dNTPs), $5 \mathrm{mM} \mathrm{MgSO} 4,100 \mathrm{nM}$ of each primer, $150 \mathrm{nM}$ of each TaqMan probe, $1 \mu \mathrm{l}$ of SuperScript III reverse transcriptase/Platinum Taq mix and $1 \mu \mathrm{l}$ of $i n-$ vitro transcribed RNA sample in a $25 \mu \mathrm{l}$ volume. Reverse transcription was carried out for $30 \mathrm{~min}$ at $48^{\circ} \mathrm{C}$ followed by a denaturation step of $2 \mathrm{~min}$ at $95^{\circ} \mathrm{C}$. The PCR amplification was then performed for 40 cycles with each cycle at $94^{\circ} \mathrm{C}$ for $15 \mathrm{~s}$ and $60^{\circ} \mathrm{C}$ for $30 \mathrm{~s}$. All reactions were carried out in triplicate using a Smart Cycler system (Cepheid, Sunnyvale, CA). The threshold cycle, $C_{t}$, values of the samples (containing $4.0 \mu \mathrm{g}$ of $E$. chaffeensis protein lysate) were averaged from values obtained from each reaction, and the promoter activity was calculated as a relative level of expression to the reference control in a separate tube. The relative level of expression was calculated using the mathematical model of relative expression ratio in real-time PCR under constant reference gene expression [31]: Ratio $=\left(E_{\text {target }}\right)$ $\triangle \mathrm{CT}$ target(control-sample), where $E$ represents the PCR efficiency of one cycle in the exponential phase and was calculated according to the equation: $E=10^{[-1 / \text { slope] }}$.

\section{Preparation of $E$. chaffeensis whole-cell soluble protein lysates}

E. chaffeensis organisms were cultivated in vitro in canine macrophage (DH82) cell lines at $37^{\circ} \mathrm{C}$ or in ISE6 tick cells as described previously $[18,56]$. The protocols for $E$. chaffeensis cell lysate preparations were similar to previously described methods for E. chaffeensis, A. phagocytophilum and other Gram negative bacterial organisms $[49,52,58]$. Twenty five $\mathrm{ml}$ of about $80-100 \% E$. chaffeensis infected cultures were harvested using glass beads. The cultures were centrifuged at 15,560 $\times g$ for $15 \mathrm{~min}$ to recover infected host cells and cell free $E$. chaffeensis organisms. To release the organisms from host cells, the pellet was resuspended in $10 \mathrm{ml} \mathrm{SPK} \mathrm{buf-}$ fer (0.5 $\mathrm{K}_{2} \mathrm{HPO} 4,0.5 \mathrm{M} \mathrm{KH}_{2} \mathrm{PO} 4$, and $0.38 \mathrm{M}$ sucrose) and sonicated twice for $30 \mathrm{sec}$ at a setting of 6.5 in a Sonic Dismembrator (Fisher Scientific, Pittsburgh, PA). The cell lysates were centrifuged at $400 \times g$ for $5 \mathrm{~min}$ and the supernatant containing cell free E. chaffeensis was filtered through a $5 \mu \mathrm{m}$ and $3 \mu \mathrm{m}$ sterile isopore membrane filters (Millipore, Billerica, MA). The filtrate containing cell free organisms was centrifuged at 15,560 $\times g$ for $15 \mathrm{~min}$ at $4^{\circ} \mathrm{C}$. The pellet containing E. chaffeensis organisms was washed twice with $1.5 \mathrm{ml}$ of lysis buffer (150 mM Tris- $\mathrm{HCl} \mathrm{pH}$ 8.0, $100 \mathrm{mM} \mathrm{KCl,} 10 \mathrm{mM}$ Magnesium Acetate, $1 \mathrm{mM}$ EDTA, 2 mM DTT and 10\% 
glycerol) and the pellet was resuspended in $1 \mathrm{ml}$ of lysis buffer containing protease inhibitors (Roche Diagnostic Labs, Indianapolis, IN). The cell suspension was sonicated four times at 8.5 setting, $30 \mathrm{sec}$ each time to lyse E. chaffeensis organisms. The cell lysates were centrifuged at $15,560 \times g$ for $15 \mathrm{~min}$ at $4^{\circ} \mathrm{C}$ to pellet the insoluble fraction and the supernatant containing soluble proteins of $E$. chaffeensis was collected into sterile micro centrifuge tubes as $25 \mu \mathrm{l}$ aliquots containing protease inhibitor mix and stored at $-80^{\circ} \mathrm{C}$ until use. Protein concentration of the protein lysates, prior to adding the protease inhibitor mix, was estimated as described above.

\section{Electrophoretic mobility shift assay (EMSA)}

DNA sequence segments spanning one or more putative regulatory sequences of $p 28$-Omp14 or $p 28$-Omp19 gene promoters were amplified from E. chaffeensis Arkansas isolate genomic DNA using sequence specific primers and 5'end biotin-labeled reverse primers (Table 1) and evaluated for their interaction with the protein lysates. EMSA experiments and detection were carried out according to established protocols $[57,58]$ with a radioactive nucleotide incorporated DNA probes or using the LightShift Chemiluminescent EMSA kit (Pierce Biotechnology, Rockford, Illinois, USA) according to the specifications of the manufacturer. The assay mixtures included a non-specific DNA (salmon sperm DNA or poly dI.dC at a high concentration of $240 \mu \mathrm{g} / \mathrm{ml}$ or 50 $\mu \mathrm{g} / \mathrm{ml}$, respectively) to eliminate non-specific interactions. Briefly, about $1 \mathrm{ng}$ of each of the full length or biotin-labeled partial upstream sequences was used in each reaction together with $5 \mu \mathrm{g}$ of the $E$. chaffeensis whole-cell protein lysate. About 50 ng of unlabeled specific probe sequences were used as competitors. Bovine serum albumin (BSA) was included in each experiment as a non-specific protein control. The protein concentration in E. chaffeensis protein lysates used in these experiments was similar to the work reported earlier $[41,49,58]$.

\section{Statistical analysis}

We carried out two-tailed t-tests with equal variances for densitometry analysis and unequal variances for the real-time RT-PCR analysis to comparatively analyse the effect of addition of $E$. chaffeensis whole cell protein lysate on transcription of $p 28-O m p 14$ (pRG147) and p28-Omp19 (pRG198) promoters.

\section{Acknowledgements}

This work is supported by National Institutes of Health grant Al070908. We thank Dr. Ming Tan of the University of California, Irvine, CA for providing the G-less cassette parent plasmid, pMT504. We also acknowledge Chuanmin Cheng for her technical assistance. This manuscript is a contribution from the Kansas Agricultural Experiment Station, number 11 283-J.

\section{Authors' contributions}

BF carried out the native RNAP isolation, bioinformatics analysis, in vitro promoter mapping studies, statistical analysis, and drafted the manuscript and compiling the appropriate references. $\mathrm{HL}$ prepared the recombinant $\sigma 70$ subunit and participated in the in vitro promoter mapping studies using $E$. coli RNAP reconstituted with the recombinant protein. LP carried out EMSA experiments. RRG conceived of the study and participated in its design and coordination, instrumental in obtaining financial support, helped in data analysis and to draft the manuscript to its final form. All authors read and approved the final manuscript.

Received: 2 December 2010 Accepted: 22 April 2011

Published: 22 April 2011

\section{References}

1. Chen SM, Dumler JS, Bakken JS, Walker DH: Identification of a granulocytotropic Ehrlichia species as the etiologic agent of human disease. J Clin Microbiol 1994, 32:589-595.

2. Dawson JE, Anderson BE, Fishbein DB, Sanchez JL, Goldsmith CS, Wilson $\mathrm{KH}$, Duntley CW: Isolation and characterization of an Ehrlichia species from a patient diagnosed with human ehrlichiosis. J Clin Microbiol 1991, 29:2741-2745.

3. Fishbein D, Sawyer L, Holland C, Hayes E, Okoroanyanwu W, Williams B, Sikes R, Ristic M, McDade J: Unexplained febrile illnesses after exposure to ticks: infection with an Ehrlichia? J Am Med Assoc 1987, 257:3100-3104.

4. Maeda K, Markowitz N, Hawley RC, Ristic M, Cox D, McDade JE: Human infection with Ehrlichia canis, a leukocytic rickettsia. N Engl J Med 1987, 316:853-856.

5. Breitschwerdt EB, Hegarty BC, Hancock SI: Sequential evaluation of dogs naturally infected with Ehrlichia canis, Ehrlichia chaffeensis, Ehrlichia equi, Ehrlichia ewingii, or Bartonella vinsonii. J Clin Microbiol 1998, 36:2645-2651.

6. Dawson JE, Biggie KL, Warner CK, Cookson K, Jenkins S, Levine JF, Olson JG: Polymerase chain reaction evidence of Ehrlichia chaffeensis, an etiologic agent of human erlichiosis, in dogs from southeast Virginia. Am J Vet Res 1996, 57:1175-1179.

7. Dawson JE, Childs JE, Biggie KL, Moore C, Stallknecht D, Shaddock J, Bouseman J, Hofmeister E, Olson JG: White-tailed deer as a potential reservoir of Ehrlichia spp. J Wildl Dis 1994, 30:162-168.

8. Dugan VG, Little SE, Stallknecht DE, Beall AD: Natural infection of domestic goats with Ehrlichia chaffeensis. J Clin Microbiol 2000, 38:448-449.

9. Kocan AA, Levesque GC, Whitworth LC, Murphy GL, Ewing SA, Barker RW: Naturally occurring Ehrlichia chaffeensis infection in coyotes from Oklahoma. Emerg Infect Dis 2000, 6:477-480.

10. Kordick SK, Breitschwerdt EB, Hegarty BC, Southwick KL, Colitz CM, Hancock SI, Bradley JM, Rumbough R, Mcpherson JT, MacCormack JN: Coinfection with multiple tick-borne pathogens in a Walker Hound kennel in North Carolina. J Clin Microbiol 1999, 37:2631-2638.

11. Dumler JS, Bakken JS: Human ehrlichioses: newly recognized infections transmitted by ticks. Annu Rev Med 1998, 49:201-213.

12. Popov VL, Chen SM, Feng HM, Walker DH: Ultrastructural variation of cultured Ehrlichia chaffeensis. J Med Microbiol 1995, 43:411-421.

13. Rikihisa Y, Zhi N, Wormser GP, Wen B, Horowitz HW, Hechemy KE: Ultrastructural and antigenic characterization of a granulocytic ehrlichiosis agent directly isolated and stably cultivated from a patient in New York state. J Infect Dis 1997, 175:210-213.

14. Zhang Jz, Popov VL, Gao S, Walker DH, Yu Xj: The developmental cycle of Ehrlichia chaffeensis in vertebrate cells. Cellular Microbiology 2007, 9:610-618.

15. Ganta RR, Peddireddi L, Seo GM, Dedonder SE, Cheng C, Chapes SK: Molecular characterization of Ehrlichia interactions with tick cells and macrophages. Front Biosci 2009, 14:3259-3273, (PMID19273271).

16. Seo GM, Cheng C, Tomich J, Ganta RR: Total, membrane, and immunogenic proteomes of macrophage- and tick cell-derived Ehrlichia chaffeensis evaluated by LC-MS/MS and MALDI-TOF methods. Infect Immun 2008, 76:4823-4832, (PMID: 18710870).

17. Singu V, Liu H, Cheng C, Ganta RR: Ehrlichia chaffeensis expresses macrophage- and tick cell-specific 28-kilodalton outer membrane proteins. Infect Immun 2005, 73:79-87. 
18. Singu V, Peddireddi L, Sirigireddy KR, Cheng C, Munderloh UG, Ganta RR: Unique macrophage and tick cell-specific protein expression from the p28/p30 Omp multigene locus in Ehrlichia species. Cell Microbiol 2006, 8:1475-87.

19. Ganta RR, Cheng C, Miller EC, McGuire BL, Peddireddi L, Sirigireddy KR, Chapes SK: Differential clearance and immune responses to tick cellderived versus macrophage culture-derived Ehrlichia chaffeensis in mice. Infect Immun 2007, 75:135-145, (PMID: 17060466).

20. $\mathrm{Yu} \mathrm{HH}$, Tan M: Sigma 28 RNA polymerase regulates hctB, a late developmental gene in Chlamydia. Mol Microbiol 2003, 50:577-584.

21. Chamberlin M, Kingston R, Gilman M, Wiggs J, deVera A: Isolation of bacterial and bacteriophage RNA polymerases and their use in synthesis of RNA in vitro. Methods Enzymol 1983, 101:540-68.

22. Richard RB: Purification and physical properties of E. coli RNA polymerase. Cold Spring Harbor Monograph Archive; RNA Polymerase 1976, 06.

23. Michael JC: RNA polymerase-an overview. Cold Spring Harbor Monograph Archive; RNA Polymerase 1976, 06.

24. Hotopp JC, Lin M, Madupu R, Crabtree J, Angiuoli SV, Eisen JA, Seshadri R, Ren Q, Wu M, Utterback TR, Smith S, Lewis M, Khouri H, Zhang C, Niu H, Lin Q, Ohashi N, Zhi N, Nelson W, Brinkac LM, Dodson RJ, Rosovitz MJ, Sundaram J, Daugherty SC, Davidsen T, Durkin AS, Gwinn M, Haft DH, Selengut JD, Sullivan SA, Zafar N, Zhou L, Benahmed F, Forberger H, Halpin R, Mulligan S, Robinson J, White O, Rikihisa Y, Tettelin H: Comparative genomics of emerging human ehrlichiosis agents. PLOS Genet 2006, 2:e21.

25. Peddireddi L, Cheng C, Ganta R: Promoter analysis of macrophage- and tick cell-specific differentially expressed Ehrlichia chaffeensis p28-Omp genes. BMC Microbiology 2009, 9:99.

26. Tan M, Engel JN: Identification of sequences necessary for transcription in vitro from the Chlamydia trachomatis rRNA P1 promoter. J Bacteriol 1996, 178:6975-6982.

27. Ding HF, Winkler HH: Purification and partial characterization of the DNAdependent RNA polymerase from Rickettsia prowazekii. The Journal of Bacteriology 1990, 172:5624-5630.

28. Koehler JE, Burgess RR, Thompson NE, Stephens RS: Chlamydia trachomatis RNA polymerase major sigma subunit. Sequence and structural comparison of conserved and unique regions with Escherichia coli sigma 70 and Bacillus subtilis sigma 43. J Biol Chem 1990, 265:13206-13214.

29. Strickland MS, Thompson NE, Burgess RR: Structure and function of the sigma-70 subunit of Escherichia coli RNA polymerase. Monoclonal antibodies: localization of epitopes by peptide mapping and effects on transcription. Biochemistry 1988, 27:5755-5762.

30. Jeyaseelan K, Ma D, Armugam A: Real-time detection of gene promoter activity: quantitation of toxin gene transcription. Nucleic Acids Res 2001, 29:e58.

31. Pfaffl MW: A new mathematical model for relative quantification in realtime RT-PCR. Nucleic Acids Res 2001, 29:e45.

32. Douglas AL, Saxena NK, Hatch TP: Enhancement of in vitro transcription by addition of cloned, overexpressed major sigma factor of Chlamydia psittaci 6BC. The Journal of Bacteriology 1994, 176:3033-3039.

33. Shen L, Feng X, Yuan Y, Luo X, Hatch TP, Hughes KT, Liu JS, Zhang YX: Selective promoter recognition by Chlamydial sigma 28 holoenzyme. The Journal of Bacteriology 2006, 188:7364-7377.

34. Wilson AC, Tan M: Functional analysis of the heat shock regulator HrcA of Chlamydia trachomatis. J Bacteriol 2002, 184:6566-6571.

35. Wilson AC, Tan M: Stress response gene regulation in Chlamydia is dependent on HrcA-CIRCE interactions. J Bacteriol 2004, 186:3384-3391.

36. Burgess RR, Jendrisak JJ: Procedure for the rapid, large-scale purification of Escherichia coli DNA-dependent RNA polymerase involving polymin P precipitation and DNA-cellulose chromatography. Biochemistry 1975, 14:4634-4638.

37. Tan $M$, Wong $B$, Engel JN: Transcriptional organization and regulation of the dnaK and groE operons of Chlamydia trachomatis. J Bacteriol 1996, 178:6983-6990.

38. Winkler HH: Protein and RNA synthesis by isolated Rickettsia prowazekii. Infect Immun 1987, 55:2032-2036.

39. Kundu TK, Kusano S, Ishihama A: Promoter selectivity of Escherichia coli RNA polymerase sigmaF holoenzyme involved in transcription of flagellar and chemotaxis genes. The Journal of Bacteriology 1997, 179:4264-4269.
40. Long SW, Zhang XF, Qi H, Standaert S, Walker DH, Yu XJ: Antigenic variation of Ehrlichia chaffeensis resulting from differential expression of the 28-kilodalton protein gene family. Infect Immun 2002, 70:1824-1831.

41. Bulyk ML: Discovering DNA regulatory elements with bacteria. Nat Biotech 2005, 23:942-944.

42. Zhou D, Yang R: Global analysis of gene transcription regulation in prokaryotes. Cellular and Molecular Life Sciences 2006, 63:2260-2290.

43. Barnard A, Wolfe A, Busby S: Regulation at complex bacterial promoters: how bacteria use different promoter organizations to produce different regulatory outcomes. Current Opinion in Microbiology 2004, 7:102-108.

44. Gralla JD: Activation and repression of E. coli promoters. Current Opinion in Genetics \& Development 1996, 6:526-530.

45. Martinez-Antonio A, Collado-Vides J: Identifying global regulators in transcriptional regulatory networks in bacteria. Current Opinion in Microbiology 2003, 6:482-489.

46. Perez-Rueda E, Collado-Vides J: The repertoire of DNA-binding transcriptional regulators in Escherichia coli K-12. Nucleic Acids Res 2000, 28:1838-1847.

47. Schüller C, Mamnun YM, Mollapour M, Krapf G, Schuster M, Bauer BE, Piper PW, Kuchler K: Global phenotypic analysis and transcriptional profiling defines the weak acid stress response regulon in Saccharomyces cerevisiae. Mol Biol Cell 2004, 15:706-720.

48. Cotter PA, Miller JF: In vivo and ex vivo regulation of bacterial virulence gene expression. Current Opinion in Microbiology 1998, 1:17-26.

49. Cheng Z, Wang X, Rikihisa Y: Regulation of type IV secretion apparatus genes during Ehrlichia chaffeensis intracellular development by a previously unidentified protein. J Bacteriol 2008, 190:2096-2105.

50. Thomas V, Samanta S, Wu C, Berliner N, Fikrig E: Anaplasma phagocytophilum modulates gp91phox gene expression through altered interferon regulatory factor 1 and PU.1 levels and binding of CCAAT displacement protein. Infect Immun 2005, 73:208-218.

51. Wang X, Cheng Z, Zhang C, Kikuchi T, Rikihisa Y: Anaplasma phagocytophilum p44 mRNA expression is differentially regulated in mammalian and tick host cells: involvement of the DNA binding protein ApxR. J Bacteriol 2007, 189:8651-8659.

52. Wang $X$, Kikuchi T, Rikihisa Y: Proteomic identification of a novel Anaplasma phagocytophilum DNA binding protein that regulates a putative transcription factor. J Bacteriol 2007, 189:4880-4886.

53. Yuan G, Wong SL: Isolation and characterization of Bacillus subtilis groE regulatory mutants: evidence for orf39 in the dnaK operon as a repressor gene in regulating the expression of both groE and dnaK. The Journal of Bacteriology 1995, 177:6462-6468.

54. Zuber U, Schumann W: CIRCE, a novel heat shock element involved in regulation of heat shock operon dnaK of Bacillus subtilis. The Journal of Bacteriology 1994, 176:1359-1363.

55. Berg D, Barrett K, Chamberlin M: Purification of two forms of Escherichia coli RNA polymerase and of sigma component. In Methods in Enzymology Nucleic Acids, Part D. Edited by: Lawrence Grossman KM. Academic Press; 1971:506-519.

56. Chen SM, Popov VL, Feng HM, Walker DH: Analysis and ultrastructural localization of Ehrlichia chaffeensis proteins with monoclonal antibodies. Am J Trop Med Hyg 1996, 54:405-412.

57. Reddy GR, Streck CP: Variability in the $28-k D a$ surface antigen protein multigene locus of isolates of the emerging disease agent Ehrlichia chaffeensis suggests that it plays a role in immune evasion. Molecular Cell Biology Research Communications 1999, 1:167-175.

58. Wainwright LA, Pritchard KH, Seifert HS: A conserved DNA sequence is required for efficient gonococcal pilin antigenic variation. Mol Microbiol $1994,13: 75-87$.

\section{doi:10.1186/1471-2180-11-83}

Cite this article as: Faburay et al.: Isolation and characterization of Ehrlichia chaffeensis RNA polymerase and its use in evaluating p28 outer membrane protein gene promoters. BMC Microbiology 2011 11:83. 